Corrosion Science, Vol. 48, No. 10, 2006, pp. 3309-3329.

ISSN: 0010-938X

DOI: $10.1016 /$ j.corsci.2005.12.003

http://www.elsevier.com/wps/find/journaldescription.cws home/260/description\#description

http://www.sciencedirect.com/science?_ob=MImg\&_imagekey=B6TWS-4JCBM1F-2-

$1 \mathrm{~J} \& \_c d i=5570 \& \_u s e r=3366836 \& \_0 r i g=b r o w s e \& \_c o v e r D a t e=10 \% 2 F 31 \% 2 F 2006 \& \_s k=999519989 \& v i e w=c \& w c h$

$\mathrm{p}=\mathrm{dGLbVzb-zSkWb \& md5=692069d99977f70196f647 \text {ea519aa7f3\&ie=/sdarticle.pdf }}$

(c) 2006 Elsevier

\title{
Effects of compressive stress on localized corrosion in AA2024-T3
}

\section{Xiaodong Liu, G.S. Frankel}

Fontana Corrosion Center, Department of Materials Science and Engineering, The Ohio State University

\begin{abstract}
The effect of compressive stress on intergranular corrosion (IGC) of AA2024-T3 was studied using a constant load and simultaneous electrochemical measurement. A specially designed electrochemical cell was used to compress a pillar-shaped sample and control the potential at a value that promoted IGC. The extent of IGC was assessed by metallurgical cross-sectional images. The effect of the compressive stress depended on the orientation of the stress relative to the elongated microstructure. Application of a compressive stress halfway to yield in the $\mathrm{S}$ or through-thickness direction significantly reduced the growth kinetics of IGC in the longitudinal direction, but did not eliminate it totally. The strain change during exposure also was used to quantify the change in radius of the cylindrical sample as a function of time during IGC growth. The effect of compression on reducing IGC was also assessed by the current density measured during potentiodynamic and potentiostatic polarization. The effects of residual compressive stress on IGC were studied using samples treated by low plastic burnishing (LPB), which produces a surface layer with high residual compressive stress. The results depended on the plane of the LPB treatment. A micro-capillary cell was used to measure corrosion behavior at different zones of the section of an LPB-treated sample. The breakdown potential was significantly higher in the zone with residual compressive stress than in the interior of the sample.
\end{abstract}

\section{Introduction}

Tensile stress is known to be a necessary component for stress corrosion cracking (SCC) [1], whereas compression can mitigate SCC initiation or decelerate propagation [2]. Compressive stress has been found to increase the incubation period for SCC of AA7075 by a factor of ten compared to a tensile stress with the same $\mathrm{K}_{1}$ [3]. Application of a compressive stress modified electrochemical reactivity and inhibited pitting initiation [4]. More practically, the development of residual compressive stress at the surface of a part by shot peening is a standard preventive measure against SCC [5-9]. Recently, surface compressive residual stress layers have been found to retard pitting corrosion and corrosion fatigue in Al alloys [10,11]. Low plasticity burnishing (LPB) is one new method that has been shown to reduce surface tensile stress and mitigate corrosion fatigue failure [12].

SCC of high strength Al alloys is almost always intergranular in nature. Intergranular corrosion (IGC) is a main form of localized corrosion in these alloys, and IGC can transition into intergranular SCC (IGSCC) under a tensile stress [13,14]. Tensile stress increases the penetration rate of IGC by an amount that depends on the orientation of the stress relative to the wrought microstructure $[13,14]$. The effect of compressive stress on IGC growth has not been studied, but it is reasonable to expect that IGC would be stifled under compression. Compression is of interest because structures such as lower airplane wings are under compression during on-field storage and are simultaneously exposed to atmospheric corrosion conditions.

The purpose of this paper is to investigate how compressive stress affects IGC in AA2024- 
T3. The relationship between the direction of applied compressive stress and the microstructure orientation is studied. The effect of residual compressive stress is also investigated.

\section{Experimental}

2.1 Effects of applied elastic compressive stress on IGC

Cylindrical samples were machined from a $19 \mathrm{~mm}$ thick wrought AA2024-T3 plate $(\mathrm{Cu}$ $4.5 \%$, Mg $1.45 \%$, Mn $0.57 \%$, Si $0.11 \%$, Fe $0.25 \%$, Zn $0.09 \%$, Ti $0.02 \%$, Cr $0.01 \%$, and other elements total $0.05 \% \max$ ) purchased from Metalmen Sales, Inc. Fig. 1(a) shows the microstructure of the wrought plate. The samples were $18 \mathrm{~mm}$ long and $8 \mathrm{~mm}$ in diameter to prevent buckling. Cylindrical samples with different axial orientations relative to the rolling direction, and thus having different orientations of the compressive load, were tested: longitudinal ( $\mathrm{L}$ or rolling direction), long transverse (T) and short transverse (S or plate throughthickness) directions, Fig. 1(b). A newly developed electrochemical cell was used to investigate the influence of compressive stress on IGC. Fig. 2 shows the configuration of the cell and compressed sample. The cell was a piece of Teflon with through-holes drilled at right angles. The height of the cell was less than the length of the sample so that the ends of the sample protruded through the cell and physically contacted the mechanical frame fixture. The sample was sealed into the cell using Miccrostop ${ }^{\mathrm{TM}}$ lacquer and the exposed area was $3 \mathrm{~cm}^{2}$. A constant load was applied using either a standard hydraulic mechanical testing machine or weights hanging from a cantilevered arm in a creep rig. The applied load was equivalent to half of the yield strength in compression. The outer surface of the cylindrical sample was exposed to the 1.0

$\mathrm{M} \mathrm{NaCl}$ solution, and IGC was promoted by the application of a constant potential of -580 $\mathrm{mV}$ SCE. Because the samples were cylindrical, the exposed surface included every orientation perpendicular to the stress axis. For instance, IGC growth in the longitudinal (L or rolling direction) and long transverse (T) directions on S planes was possible for the S samples. Crosssectional optical microscopy was used to characterize the depth of IGC in the samples after the experiments.

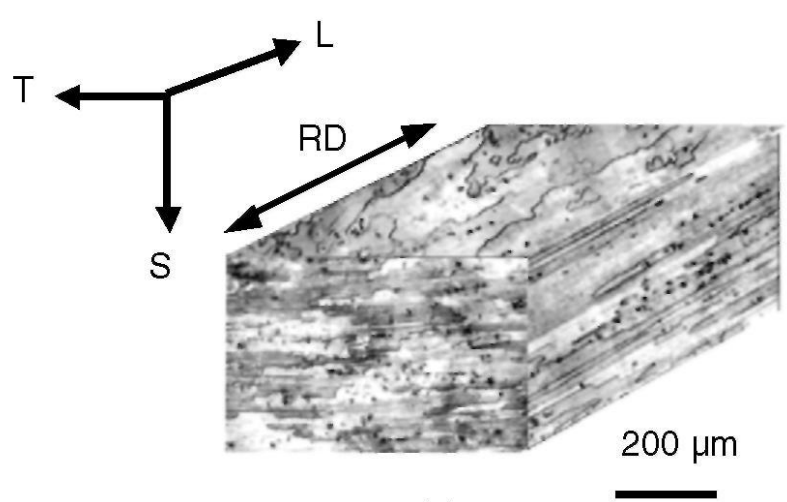

(a)

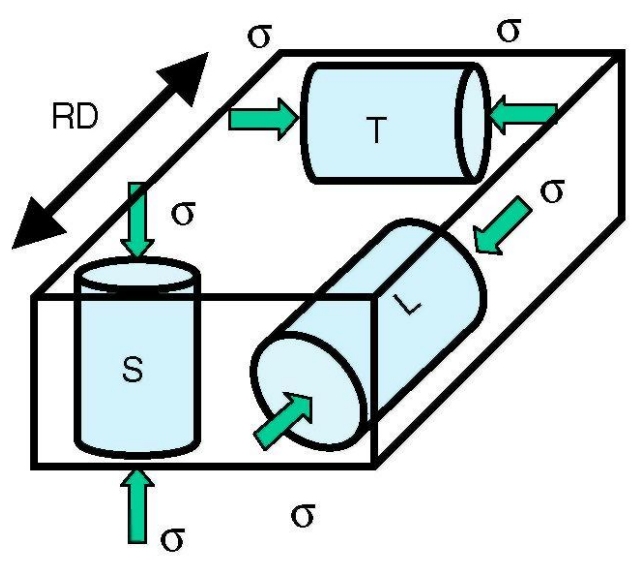

(b)

Fig. 1. Microstructure and orientations of wrought plate AA2024-T3. (a) Microstructure, (b) notation and configuration of tested sheet sample. 


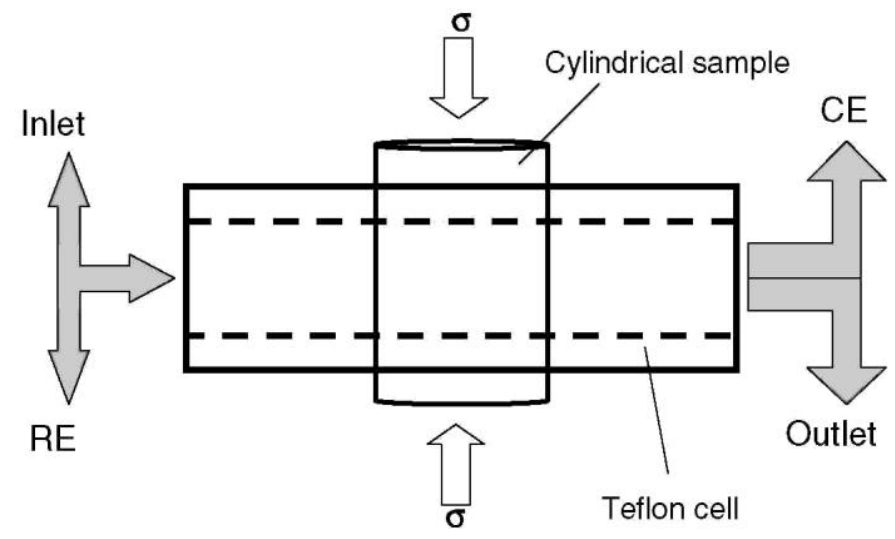

Fig. 2. Schematic of specially designed electrochemical cell made of Teflon used in compression experiments.

Because of the small volume of the cell, the $1.0 \mathrm{M} \mathrm{NaCl}$ solution was circulated continuously from a reservoir through the cell past the sample. A Pt counter electrode and saturated calomel reference electrode (SCE) were located close to the sample. The circulation rate was about $55 \mathrm{ml} / \mathrm{min}$. After applying the load and letting the system stabilize at a constant strain, the potential was applied and the anodic current was recorded.

The strain change during the experiment was measured by a 1-in. strain gauge extensometer for tests in the hydraulic testing machine and by a linear variable differential transformer (LVDT) for the tests in the constant load creep rig [15]. Since the extensometer gauge length was greater than the sample length, Type 416 stainless steel shims were used between the ends of the sample and the platens of the hydraulic testing machine. Such shims were not needed for the LVDT. As IGC penetrated into the sample, the load-bearing area decreased, resulting in an increase in stress at constant load and thus an increase in strain. The IGC growth resulted in a decrease in effective radius as a function of time, $\Delta r(t)=r_{\mathrm{o}}-r(t)$, where $r_{\mathrm{o}}$ is the original radius of the cylindrical sample, and $r(t)$ is the effective radius as a function of time. As described below, $\Delta r(t)$ can be determined by the length change of the cylindrical sample, $\Delta l(t)$, which is the displacement measured by the extensometer or LVDT.

\section{Effects of residual compressive stress on IGC}

Residual compressive stress was generated by treating samples with low plasticity burnishing (LPB). The LPB treatment was performed at Lambda Technologies, Cincinnati, $\mathrm{OH}$. LPB produces a layer of compressive residual stress of high magnitude and depth with minimal cold work by rolling a smooth ball across the surface under a normal force sufficient to plastically deform the surface of the material [11]. Hertzian loading creates a layer of compressive residual stress to a depth exceeding $1 \mathrm{~mm}$ [12].

Surfaces with two different orientations were treated by LPB. For $\mathrm{S}$ samples, the $\mathrm{S}$ or short transverse face was treated by LPB. To eliminate complications associated with microstructural differences near the surface of the as-received wrought plate, the S samples, with dimensions of $25.4 \times 50.8 \times 8.5 \mathrm{~mm}$, were cut from the middle of the plate. The direction of the LPB treatment was either perpendicular to or along the rolling direction for the treatment of $S$ surfaces. For L samples, the L or longitudinal face was rolled by LPB in the short transverse 
direction. Prior to applying LPB, all samples were polished to $6 \mu \mathrm{m} \mathrm{SiC} \mathrm{papers} \mathrm{in} \mathrm{ethanol.}$ Compressive residual stresses were found within a depth of $800 \mu \mathrm{m}$ from the LPB-treated surface [16].

Regions with and without compressive residual stress on cross sections of LPB-treated surfaces were characterized by potentiodynamic polarization in aerated $1 \mathrm{M} \mathrm{NaCl}$ at scanning rate of $10 \mathrm{mV} / \mathrm{s}$ using a capillary microcell $[17,18]$ with a capillary of diameter $70 \mu \mathrm{m}$.

\section{Results}

\subsection{Polarization measurements under compressive stress}

The anodic polarization curves for cylindrical $\mathrm{S}$ samples with and without compressive stress are shown in Fig. 3. For these cylindrical $\mathrm{S}$ samples, the exposed sidewall area is a combination of $\mathrm{L}$ and $\mathrm{T}$ surfaces. The polarization curve for a flat, unstressed $\mathrm{L}$ sample is also shown in Fig. 3 for comparison. The open circuit potential (OCP) measured for the unstressed flat L sample was lower than the others because that measurement was made in deaerated solution, whereas the measurements on the cylindrical samples were in aerated solution. Note that the measurements in the compression cell were made only in aerated solution owing to the difficulties in deaerating this circulating system. The unstressed flat $\mathrm{L}$ sample exhibited two breakdown potentials. The lower breakdown potential in AA3034-T3 has been attributed to transient $S$ phase attack and the higher breakdown potential to stable IGC and pitting [19]. Since the attack associated with the lower breakdown is transient in nature, it is not seen in aerated

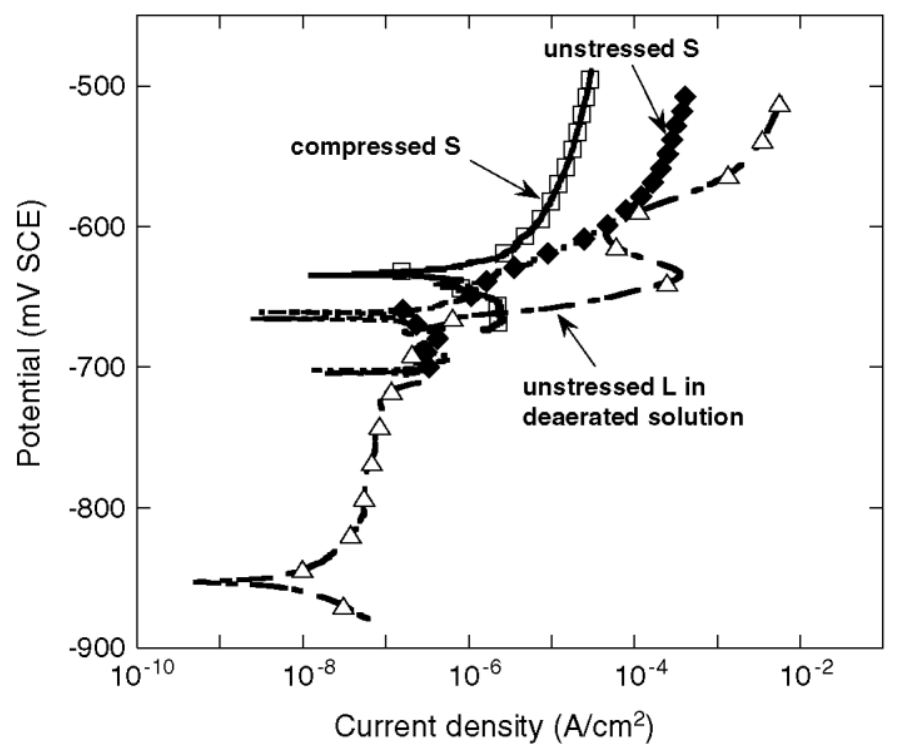

Fig. 3. Anodic polarization curves of AA2024-T3 in $1 \mathrm{M} \mathrm{NaCl}$ at $0.1 \mathrm{mV} / \mathrm{s}$. Squares are from $\mathrm{S}$ cylindrical sample under compression in aerated solution; diamonds are from $\mathrm{S}$ cylindrical sample in compression cell but with no applied stress, in aerated solution; triangles are from flat unstressed L sample in deaerated solution.

solutions. The current density of the unstressed $\mathrm{S}$ compression sample (which has $\mathrm{L}$ and $\mathrm{T}$ exposed sides) in aerated solution was in the same range as that for the unstressed flat L sample in deaerated solution near the second breakdown potential, but the current for the unstressed flat sample was higher at higher potentials. The OCP of the compressed sample was higher than that of the unstressed $\mathrm{S}$ compression sample, and the anodic current density was lower by about a 
factor of 10 .

\subsection{Effects of applied compressive stress on IGC}

Cylindrical samples subjected to a constant compressive load and exposed to $1 \mathrm{M} \mathrm{NaCl}$ at $-580 \mathrm{mV}$ SCE for $10 \mathrm{~h}$ were analyzed to study the growth kinetics of IGC under compression. Fig. 4 shows a compressive stress-strain curve for an AA2024-T3 cylindrical sample having axial orientation in the $\mathrm{S}$ direction. The Young's modulus, E, was $72.4 \mathrm{GPa}$. A load of $1020 \mathrm{~kg}$ was chosen to apply to the samples, as this represents a stress of $200 \mathrm{MPa}$, which is about halfway to the yield stress. Fig. 5 shows optical microscopy images of axial sections of a compressed S sample after $10 \mathrm{~h}$ of polarization. The stress was applied vertically in these images and the perpendicular axial sections show IGC depth in the $\mathrm{L}$ and $\mathrm{T}$ directions. It is clear that the primary form of corrosion was IGC. These images indicate that the depth of IGC attack was somewhat greater in the $\mathrm{L}$ direction compared to that in the $\mathrm{T}$ direction. The lengths of many individual IGC sites in the $\mathrm{L}$ and $\mathrm{T}$ directions were measured for these samples exposed for $10 \mathrm{~h}$ and are given as average values in Fig. 6. Also shown in Fig. 6 for comparison are foil penetration data, which represent the depth of IGC growth in the $\mathrm{L}$ and $\mathrm{T}$ directions as a function of time for unstressed samples [20]. Actually, the foil penetration experiment measures the time

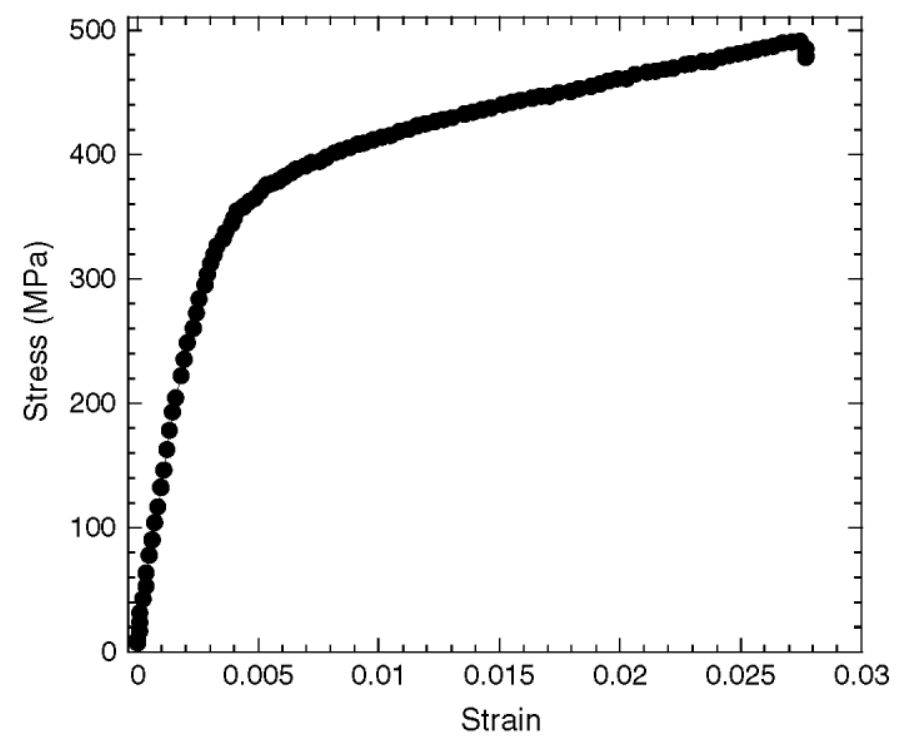

Fig. 4. Stress-strain curve in compression for S oriented AA2024-T3 pillar sample.

for the first site to penetrate the tested foil, so only the fastest growing site is sensed in each experiment [21-23]. In contrast, the sectioning method determines the depth of IGC on only the sectioned planes, so it is likely that the fastest growing site in the sample was not detected. Moreover, the measurements depend on the resolution of the cross-sectional images. Nonetheless, the data in Fig. 6 indicate that the IGC growth rates in the L and T directions in a compressed S sample are considerably slower than IGC measured during foil penetration experiments on unstressed samples. Fig. 7 shows sections of S samples after 20 or $23 \mathrm{~h}$ exposure in $1 \mathrm{M} \mathrm{NaCl}$ at $-580 \mathrm{mV} \mathrm{SCE}$ with or without simultaneous application of compressive stress. The sections are oriented to show IGC growth in the L direction. Both the depth and density of IGC attack were less in the sample that was stressed in compression during exposure. 
Fig. 8 shows optical cross-sectional images for a compressed L sample after polarization for $10 \mathrm{~h}$. Longitudinal rather than axial cross sections were used for analysis of IGC in this orientation. Fig. 8(a), a macro section of the tested sample, shows that the material loss primarily aligned along the $\mathrm{T}$ or long transverse direction. Higher magnification cross sections for the $\mathrm{L}$ sample given in Fig. 8(b) and (c) show that the primary form of corrosion was IGC along the T direction. The lengths of IGC sites growing in the T direction were measured from several cross sections. Some oval-shaped dark spots are found in Fig. 8(c) along the IGC path. These spots are regions attacked during the cross-sectional polishing by a corrosive product that oozed out of the grain boundary crevices [24], and are not regions of broadened intergranular attack. Fig. 9 shows the data along with data generated from foil penetration experiments on unstressed samples for comparison [20]. Similar to samples with stress in the S direction, the growth of IGC in the T direction was lower in the presence of compressive stress in the $\mathrm{L}$ direction compared to unstressed samples. The compressive stress decreased the rate of IGC growth in the T direction by about a factor of 2 .

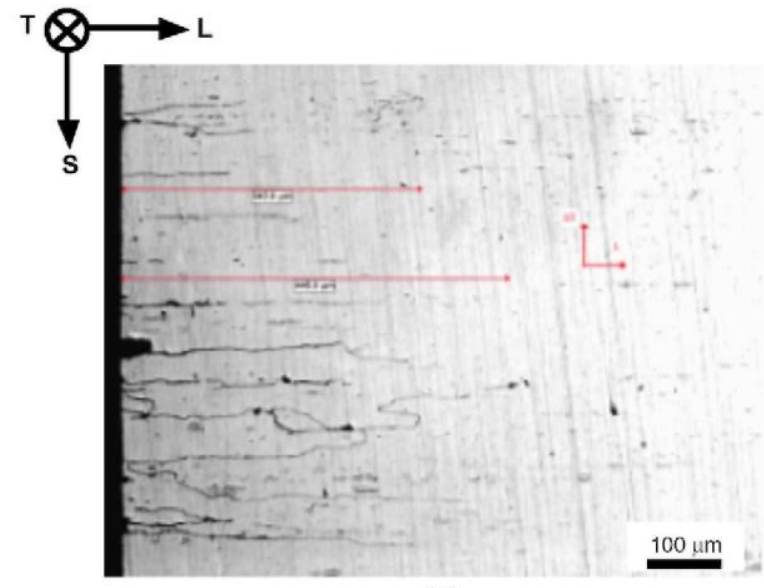

(a)

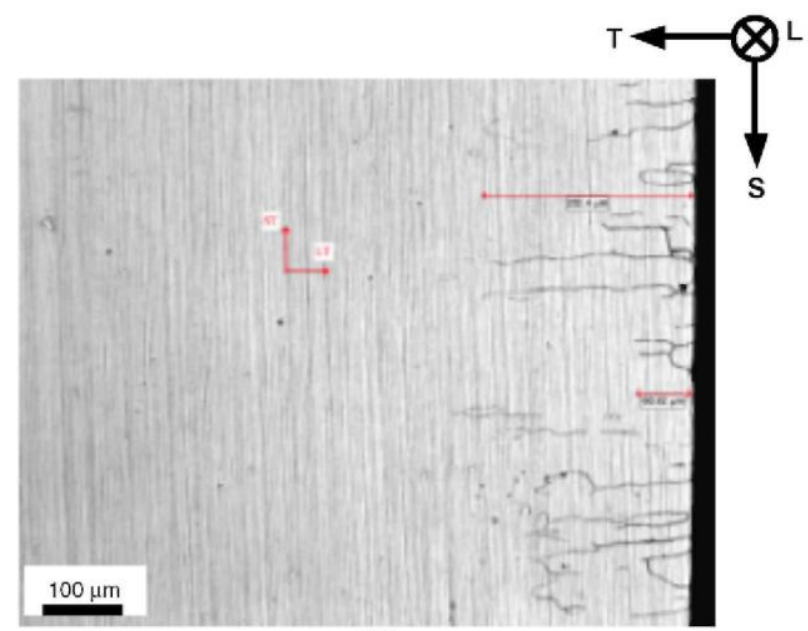

(b)

Fig. 5. Optical microscopy images of axial sections of compressed S sample after $10 \mathrm{~h}$ in $1 \mathrm{M} \mathrm{NaCl}$ at $580 \mathrm{mV}$ SCE. Compressive load was applied in S direction from top to bottom. (a) Section showing IGC growth in the L direction; (b) section showing IGC growth in T direction. 
Cross sections of a compressed $\mathrm{T}$ sample after $10 \mathrm{~h}$ of exposure in $1 \mathrm{M} \mathrm{NaCl}$ at -580 $\mathrm{mV}$ SEC are given in Fig. 10. Longitudinal sections are also appropriate for viewing IGC in a sample of this orientation where it grows primarily in the L direction. Fig. 11 shows the depth of IGC in the $\mathrm{L}$ direction along with the data from foil penetration experiments on unstressed $\mathrm{L}$ samples [20]. The decrease in IGC growth rate in the L direction for the compressed T sample relative to the stress-free sample is much less than the effect of compressive stress in the other orientations.

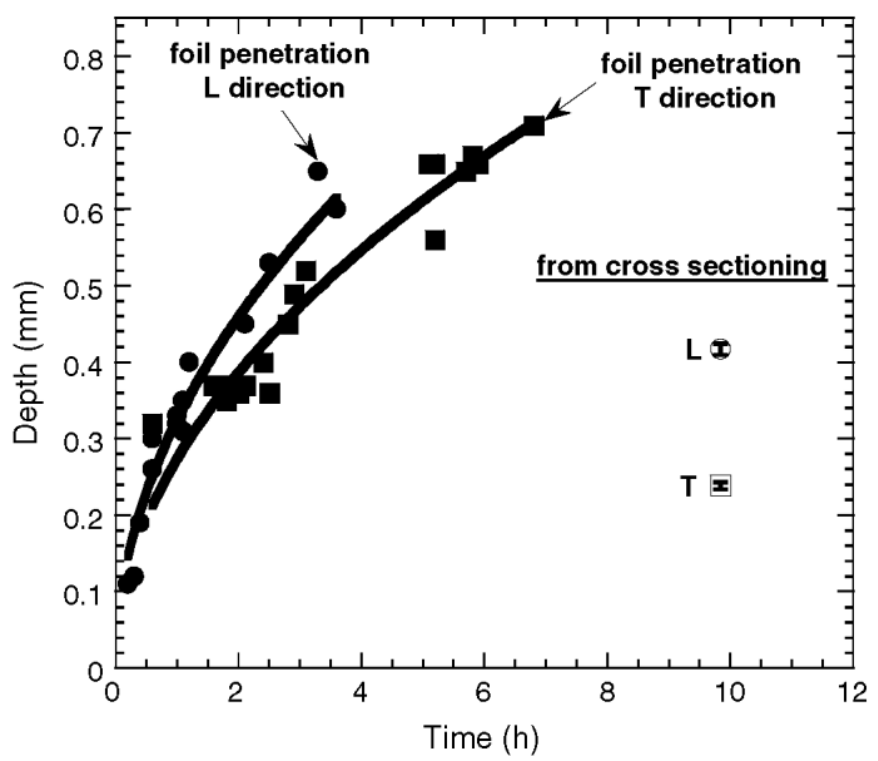

Fig. 6. Length of IGC growth in $\mathrm{L}$ and $\mathrm{T}$ direction from cross-sectioning compressed $\mathrm{S}$ sample after $10 \mathrm{~h}$ exposure. The opened symbols are average values of five sites each for the $\mathrm{L}$ and $\mathrm{T}$ directions and the bars represent the standard deviation. Data from foil unstressed penetration experiments on $\mathrm{L}$ and $\mathrm{T}$ samples [19] are shown for comparison.

To characterize the morphology of IGC with a compressive load, an S sample was fractured in tension in air after potentiostatic polarization under compression for $50 \mathrm{~h}$ at -580 $\mathrm{mV} \mathrm{SCE}$ in $1 \mathrm{M} \mathrm{NaCl}$. A typical image of the IGC region before the ductile overload region is given in Fig. 12. A large number of rod shaped particles, identified by scanning transmission electron microscopy as $\mathrm{Al}-\mathrm{Cu}-\mathrm{Mn}$ particles [24,25], were distributed on grain facets, which is similar to the fracture surface observed for similar experiments with an applied tensile stress $[25,26]$. The attack is certainly a form of IGC, and the similarity in surface morphology suggests that the corrosion mechanism is similar, i.e., that intergranular corrosion propagation under compressive stress is a kind of intergranular SCC (IGSCC). More rationale for describing this IGC under compression as IGSCC is given in Section 5.

\subsection{Measurement of IGC growth kinetics using strain change}

During the constant load tests, the compressive strain was found to increase with time even though the applied stress was in the middle of the elastic range. From the basic principles of elasticity 


$$
\varepsilon=\frac{\sigma}{E}=\frac{F}{E A}=\frac{\Delta l}{l_{\mathrm{o}}}
$$

where $\varepsilon$ is elastic strain, $\sigma$ is elastic stress, $E$ is Young's modulus, $F$ is the load, $A$ is the cross section of the cylindrical sample, $\Delta l$ is the change in length along the compressive

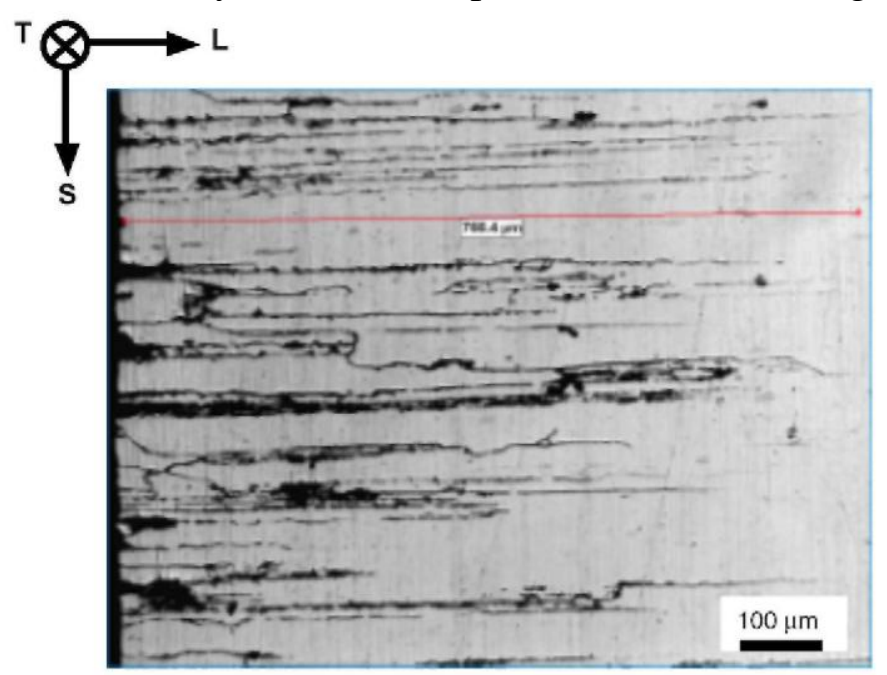

(a)

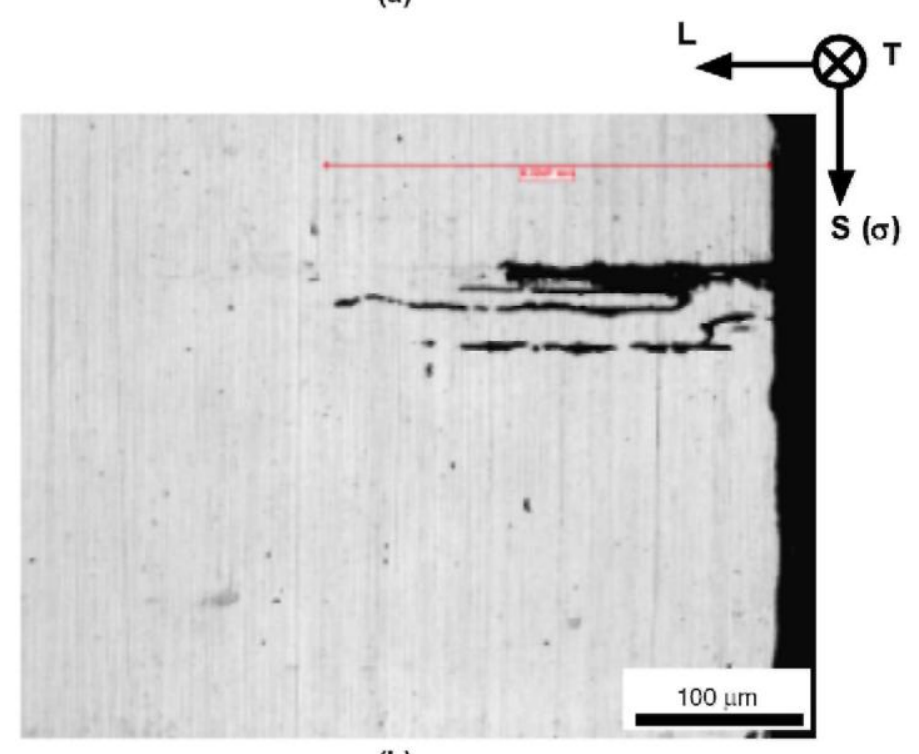

stress

(b)

Fig. 7. Comparison of cross-sectional images $\mathrm{S}$ samples with and without $\mathrm{S}$ compressive load in $1 \mathrm{M} \mathrm{NaCl}$ at -580 $\mathrm{mV}$ SCE. Compressive load was applied in S direction from top to bottom. (a) Unstressed S sample for $20 \mathrm{~h}$; (b) S sample subjected to compressive load for $23 \mathrm{~h}$.

direction and $l_{\mathrm{o}}$ is the original length. Consider an S-oriented sample with IGC growing inward from the outer surface along the $\mathrm{L}$ and $\mathrm{T}$ directions. The effective radius of the round cross section of the cylindrical sample decreases as the corrosion process consumes load-bearing 
cross-sectional area from the outer surface. Assuming that the IGC attack is uniform along the length of the exposed surface of the sample, the effective change in radius or depth of IGC attack

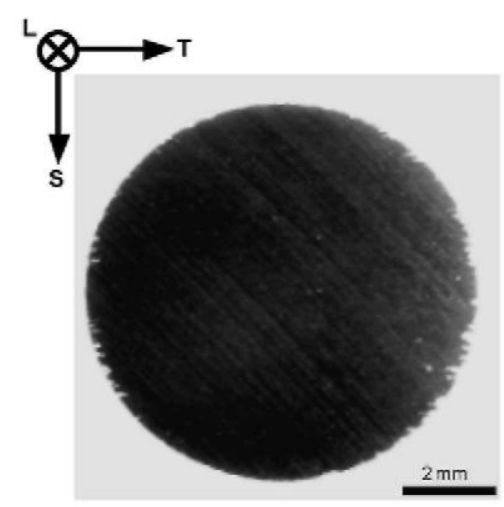

(a)

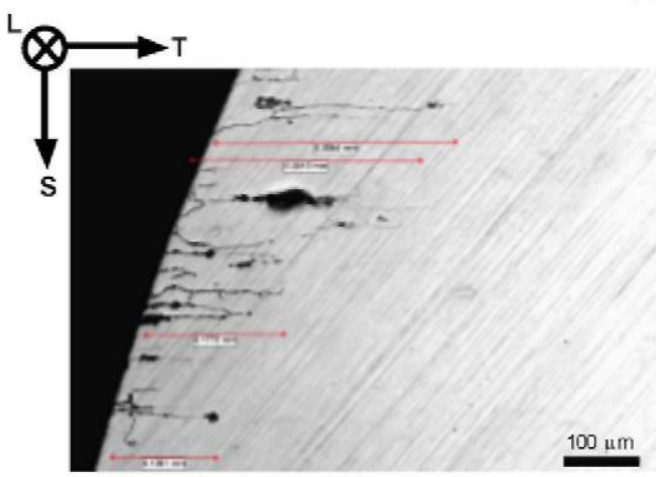

(b)

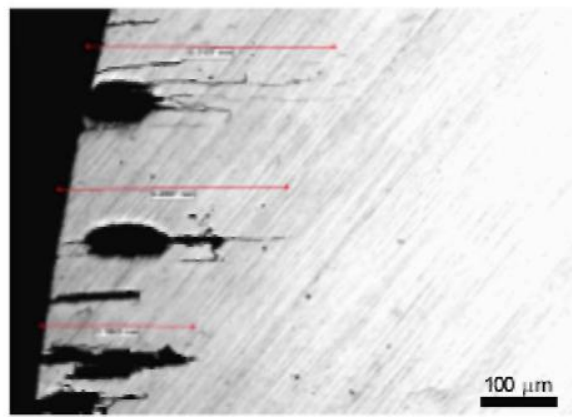

(c)

Fig. 8. Optical microscopy images of longitudinal sections of compressed L sample after $10 \mathrm{~h} \mathrm{in} 1 \mathrm{M} \mathrm{NaCl}$ at -580 $\mathrm{mV}$ SCE. Compressive load was applied in $\mathrm{L}$ direction perpendicular to the page. (a) Macro section showing orientation of IGC; $(b, c)$ two higher magnification images showing IGC growth in the T direction.

is $\Delta r(t)$ and the effective radius of the unattacked core region can be defined as $r(t)=r_{o}-\Delta r(t)$, where $r_{o}$ is the original radius. Substituting above

$$
\frac{\Delta l}{l_{\mathrm{o}}}=\frac{F}{E \pi\left(r_{\mathrm{o}}-\Delta r(t)\right)^{2}}
$$

Solving for $\Delta r(t)$, the change in radius or depth of IGC can be determined from the strain or length change of the sample with time:

$$
\Delta r(t)=r_{\mathrm{o}}-\sqrt{\frac{F l_{\mathrm{o}}}{E \pi \Delta l(t)}}
$$


In summary, as IGC proceeds inwards from the surface of an $\mathrm{S}$ sample along the $\mathrm{L}$ and $\mathrm{T}$ directions, the load-bearing cross section decreases, the stress increases in the elastic region, and the strain increases, which can be measured by a strain gauge or LVDT. So the change in strain with time can be converted to a rate of IGC growth.

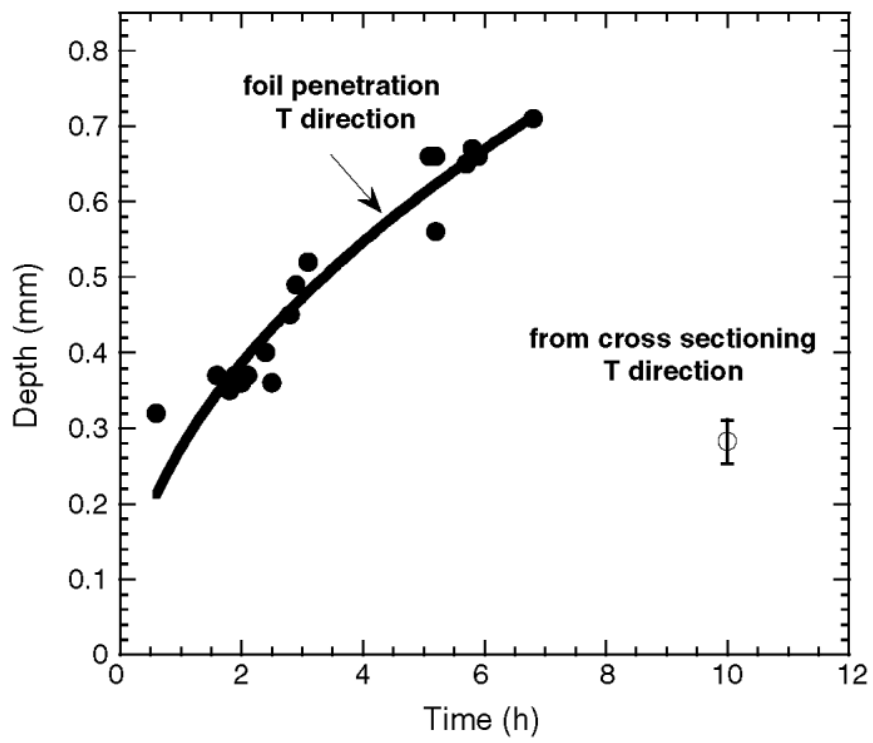

Fig. 9. Length of IGC growth in L direction from cross-sectioning compressed $\mathrm{L}$ sample after $10 \mathrm{~h}$ exposure. The opened symbol is the average value of seven sites the bars represent the standard deviation. Data from foil unstressed penetration experiments on T samples [19] are shown for comparison.

Fig. 13 shows the measured strain and calculated effective radius with time for a compressed S sample in $1 \mathrm{M} \mathrm{NaCl}$ at $-580 \mathrm{mV} \mathrm{SCE}$ over $15 \mathrm{~h}$. Clearly, the measured strain increased and thus the calculated effective radius, $r(t)$ decreased with time. Fig. 14 compares various measures of IGC growth. The filled diamonds are the radius change values calculated from the strain in the experiment shown in Fig. 14, but indicated here as IGC depth. Shown as filled circles are the endpoints from other experiments, also calculated from the change in strain. These points line up with an extrapolation of the data from the first experiment. The depths of individual IGC sites measured from sections of different experiments are shown as open squares. The IGC depths determined by sectioning and by strain change, which were generated independently, are quite close. In fact, the IGC depth calculated from the stain change simulates an average localized corrosion depth in the $\mathrm{L}$ and $\mathrm{T}$ directions of the round samples, which should be in the range of the observed IGC. Some low values of IGC length (open square symbols) in Fig. 14 indicate that the cross-sectioning at random planes did not find the longest IGC, which controlled the load-bearing area and thus the strain change.

\subsection{Effects of residual compressive stress on IGC}

The effects of applied compressive stress on IGC are difficult to investigate in situ because of the physical constraints of applying a compressive load. The effects of compression can more-easily be studied by using residual stress. Residual compressive stress, such as 


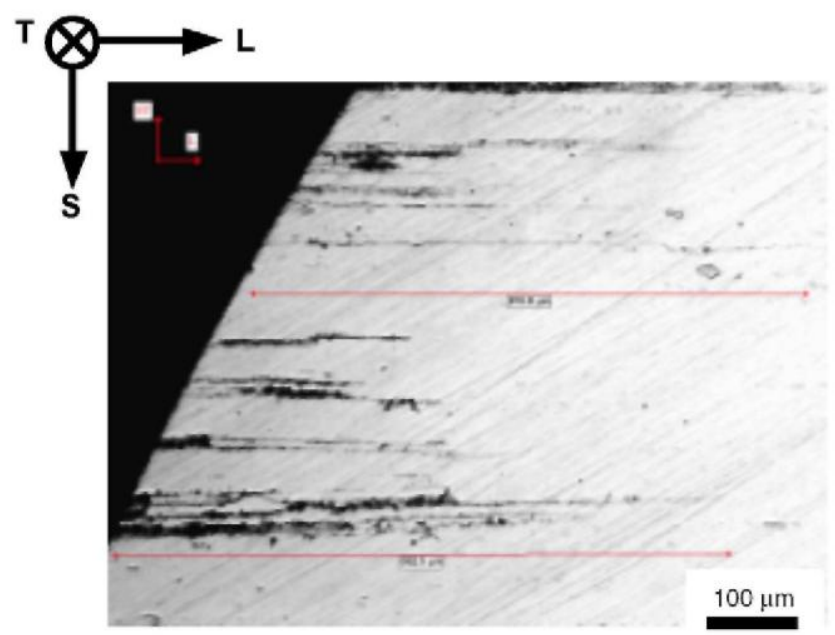

(a)

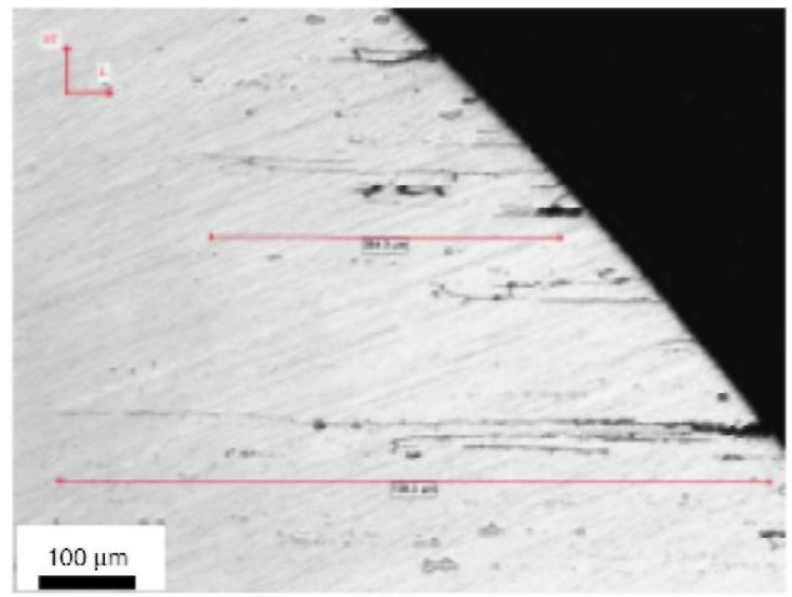

(b)

Fig. 10. Optical microscopy images of longitudinal sections of compressed $\mathrm{T}$ sample after $10 \mathrm{~h}$ in $1 \mathrm{M}$ $\mathrm{NaCl}$ at $-580 \mathrm{mV}$ SCE. Compressive load was applied in $\mathrm{T}$ direction perpendicular to the page. (a,b) Two images showing IGC growth in the L direction.

developed by methods like shot peening, is commonly used on surfaces of engineering structures to prevent corrosion fatigue [9,10]. Like shot peening, low plastic burnishing (LPB) imparts a high-magnitude residual compressive stress on the surface of a sample with minimal cold work [12]. In this study, LPB was performed on flat surfaces of AA2024-T3 with faces perpendicular to the $\mathrm{S}$ or L direction. As stated in the experimental section, X-ray diffraction analysis indicated that the samples had a compressive stress region extending $800 \mu \mathrm{m}$ into the surface with maximum values of compressive stress and cold work of $50 \mathrm{ksi}$ and 9\%, respectively [16]. Fig. 15 shows cross-sectional optical micrographs of the LPB treated samples. It is difficult to distinguish changes in microstructure at the treated surfaces, which are the top edges of each image.

Fig. 16 shows potentiodynamic polarization curves in deaerated $1 \mathrm{M} \mathrm{NaCl}$ for $\mathrm{S}$ surfaces with and without LPB treatment. The LPB treatment decreased the passive current density by a factor of about 3 . Both curves exhibit passivation and breakdown during potentiodynamic 


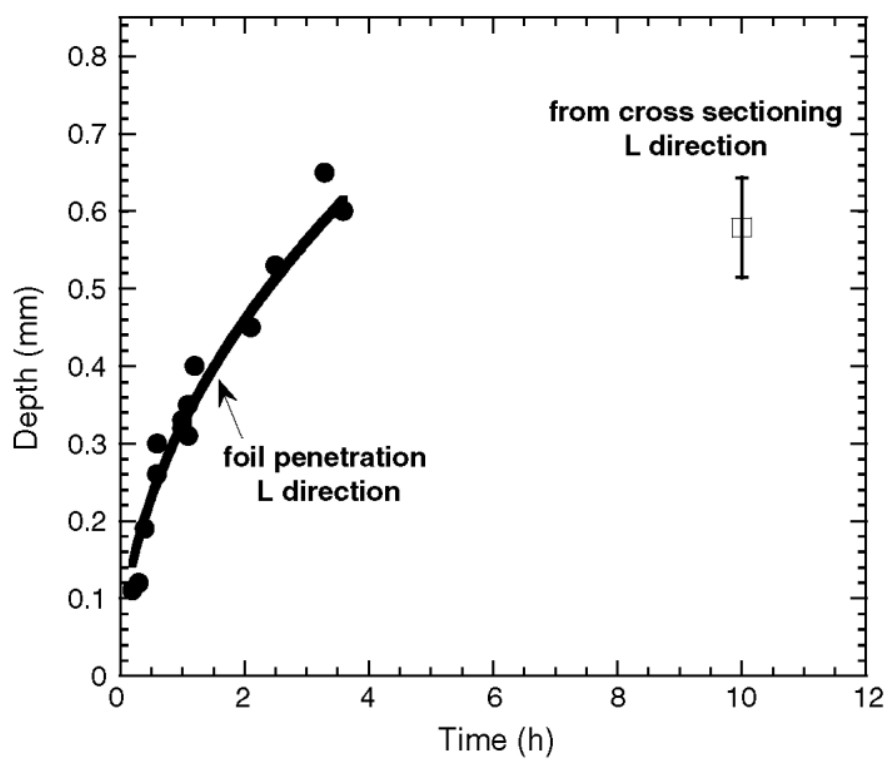

Fig. 11. Length of IGC growth in L direction from cross-sectioning compressed $\mathrm{T}$ sample after $10 \mathrm{~h}$ exposure. The opened symbol is the average value of five sites the bars represent the standard deviation. Data from foil unstressed penetration experiments on L samples 19 are shown for comparison.

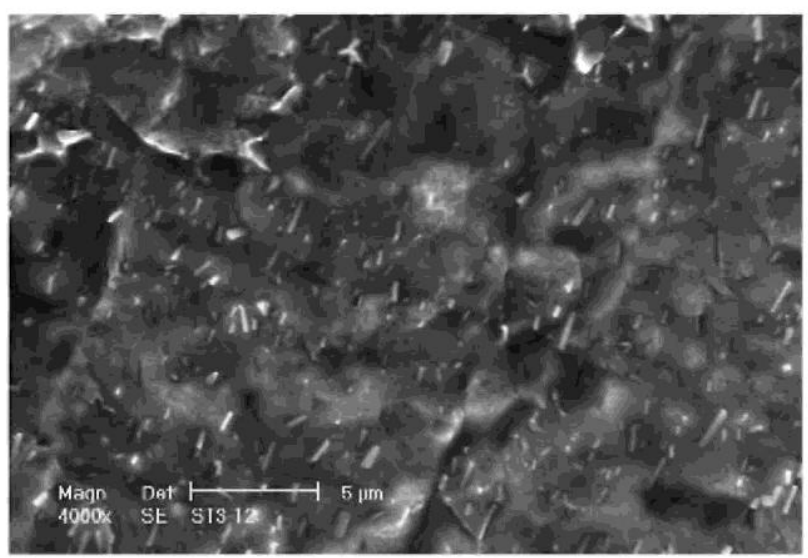

Fig. 12. Morphology of a compressed S sample after $50 \mathrm{~h}$ at $-580 \mathrm{mV} \mathrm{SCE}$ in $1 \mathrm{M} \mathrm{NaCl}$.

polarization. Moreover, the treated sample exhibited only one breakdown potential; the current increased at a value between the breakdown potentials for the untreated sample, and the currents merged at potentials above the second breakdown. The phenomenon associated with the first breakdown in AA2024-T3, transient dissolution of S phase particles, apparently did not take place on the LPB treated sample.

LPB treated S-oriented samples were potentiostatically polarized at $-580 \mathrm{mV}$ SCE in 1 $\mathrm{M} \mathrm{NaCl}$ for $12 \mathrm{~h}$. No difference in current density was measured at this potential in the polarization curves. Fig. 17 shows cross-sectional micrographs of exposed S samples with 


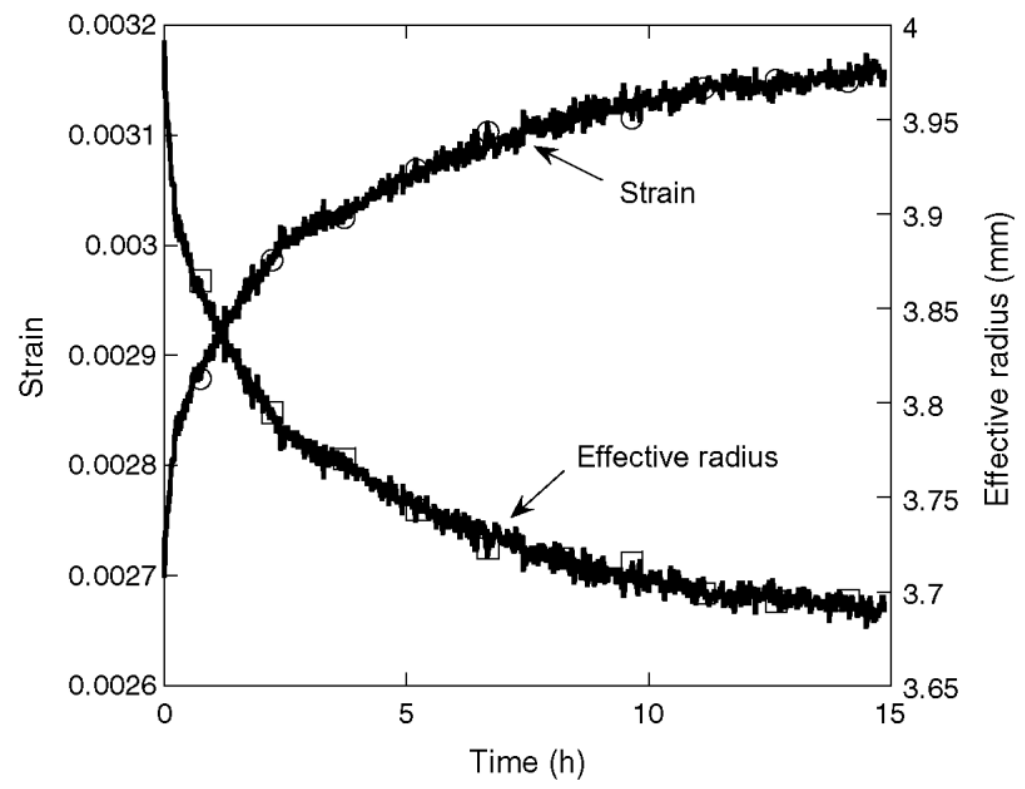

Fig. 13. Strain transient and calculated effective radius with time for compressed $\mathrm{S}$ sample in $1 \mathrm{M} \mathrm{NaCl}$ at $-580 \mathrm{mV}$ SCE.

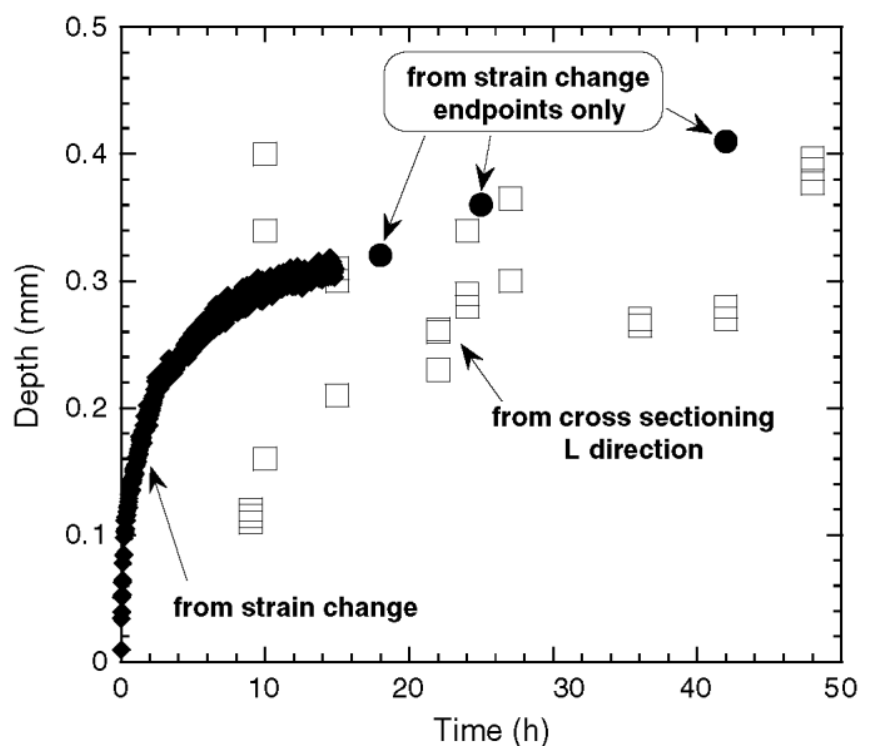

Fig. 14. Depth of IGC in L direction for AA2024-T3 in $1 \mathrm{M} \mathrm{NaCl}$ at $-580 \mathrm{mV}$ SCE. Diamonds are calculated depth from strain change of $\mathrm{S}$ compression sample. Open circles are also from strain change, but are end points of separate experiments. Open squares are from cross-sectioning S compression samples. Filled squares are unstressed foil penetration data for AA2024-T3 samples in L direction. 


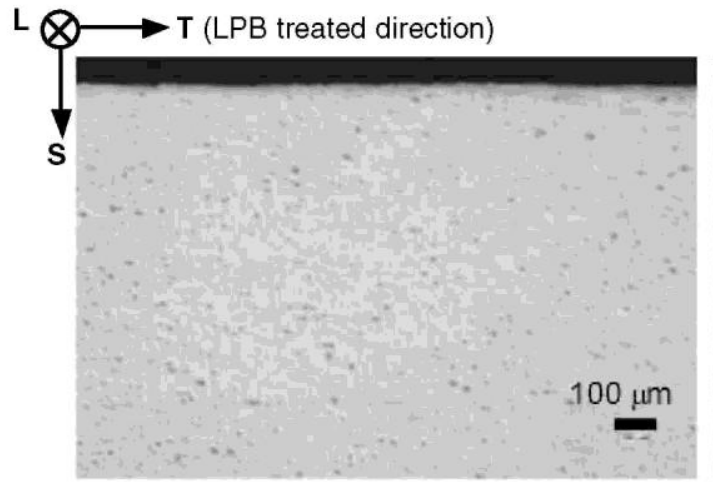

(a)

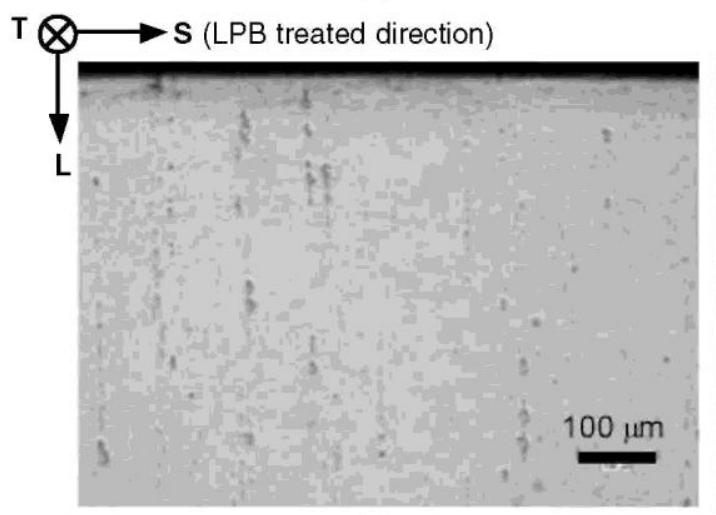

(c)

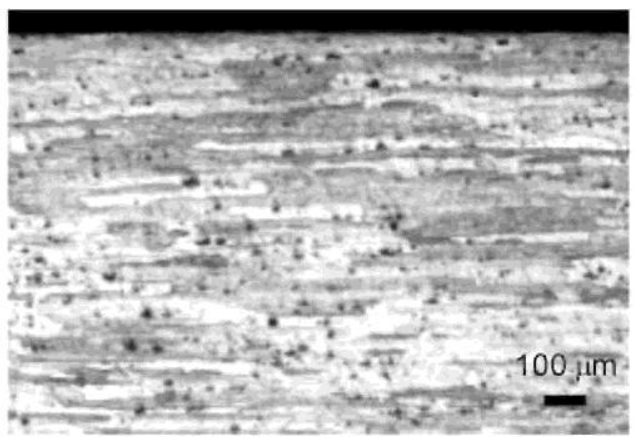

(b)

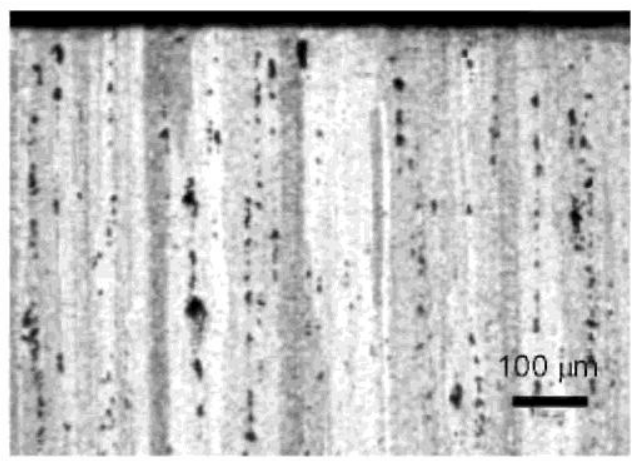

(d)

Fig. 15. Cross-sectional optical micrographs of LPB treated samples. (a) Unetched and (b) etched sections of sample treated on S surface in T direction; (c) unetched and (d) etched sections of sample treated on $\mathrm{L}$ surface in $\mathrm{S}$ direction.

and without prior LPB treatment. The cross-sectioning was performed to expose $\mathrm{L}$ sections. The untreated S sample in Fig. 17(a) exhibited an interconnected network of IGC, with some grains lifting off, perhaps by exfoliation. The sample with prior LPB treatment, shown Fig. 17(b), did not exhibit the IGC network. It appears that the surface lost material almost to a uniform depth. The rate of exfoliation has been found to increase with applied compressive stress [27], so it is possible that the extent of IGC is less but exfoliation is greater. The depth of attack for both samples exhibited considerable variability, but the mean depth for 22 points along the LPBtreated sample, $141 \pm 42 \mu \mathrm{m}$, was significantly less than that for the untreated sample, $193 \pm 31$ $\mu \mathrm{m}$.

Fig. 18 shows cross-sectional micrographs of $\mathrm{L}$ surfaces following potentiostatic polarization at $-580 \mathrm{mV} \mathrm{SCE}$ in $1 \mathrm{M} \mathrm{NaCl}$ for $12 \mathrm{~h}$. The LPB treatment was applied by rolling in the S direction. The sample without LPB treatment exhibited IGC growing straight down the $\mathrm{L}$ direction, whereas the grains near surface of the LPB treated sample were bent in different directions following the electrochemical treatment. The depth of attack in the two samples was similar. The potentiodynamic polarization curves for the two L surfaces were also very similar, Fig. 19. Both exhibited two breakdown potentials, but the second breakdown potential was 


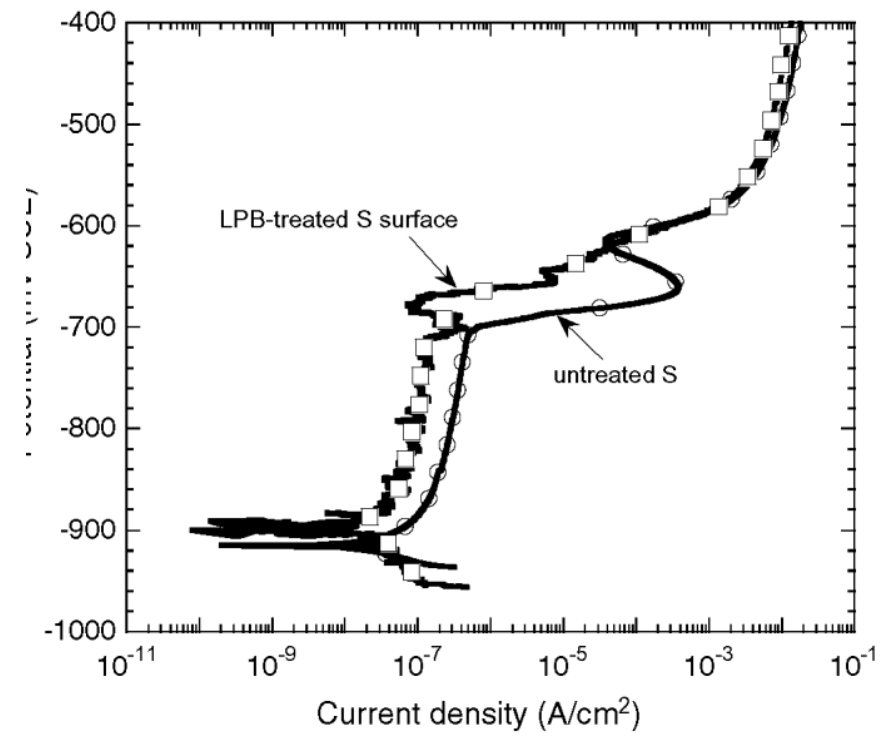

Fig. 16. Anodic polarization curves of AA2024-T3 S surfaces with and without LPB treatment in deaerated $1.0 \mathrm{M} \mathrm{NaCl}$ at $0.1 \mathrm{mV} / \mathrm{s}$.

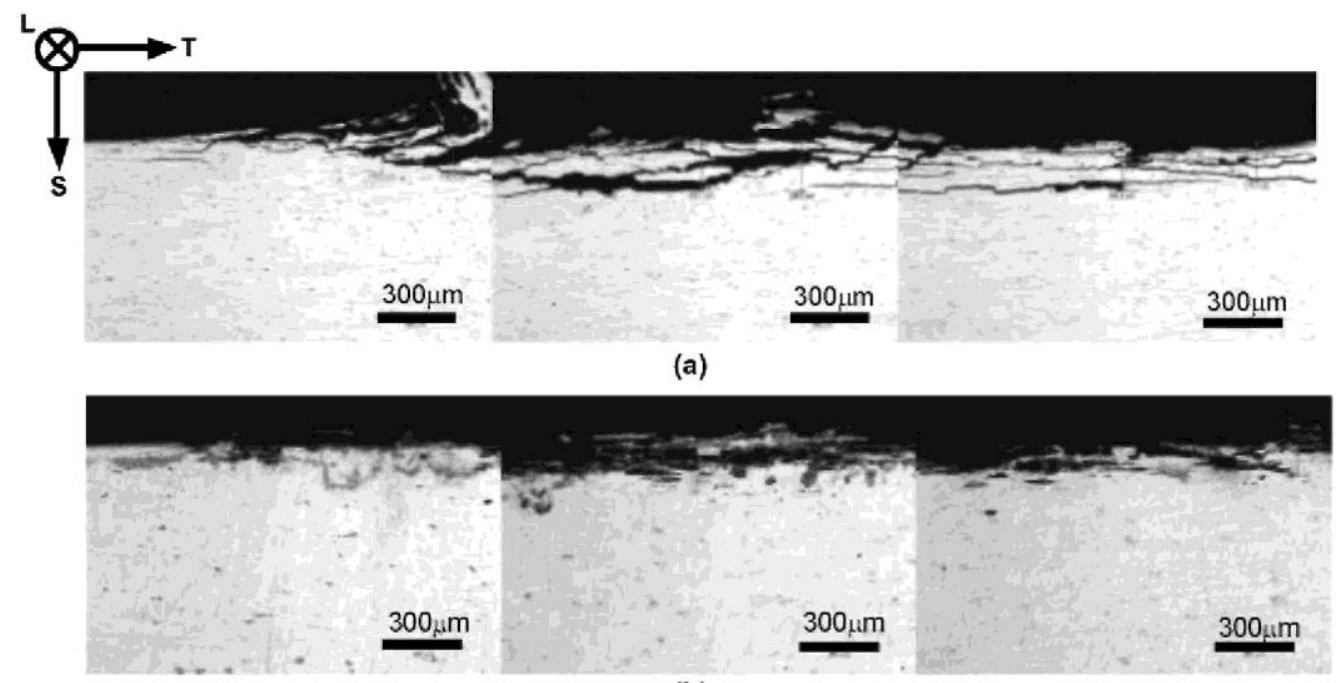

(b)

Fig. 17. Cross-sectional optical micrographs of AA2024-T3 S surfaces after potentiostatic polarization at - $580 \mathrm{mV} \mathrm{SCE}$ in $1.0 \mathrm{M} \mathrm{NaCl}$ for $12 \mathrm{~h}$ : (a) no LPB treatment, (b) LPB-treated S sample.

lower for the LPB treated sample, and the current was higher just above the second breakdown. These results are in contrast to the benefits of applied compressive stress on L surfaces described above, and suggest that there can be a complex interaction between the stress direction and micro-structure orientation. 


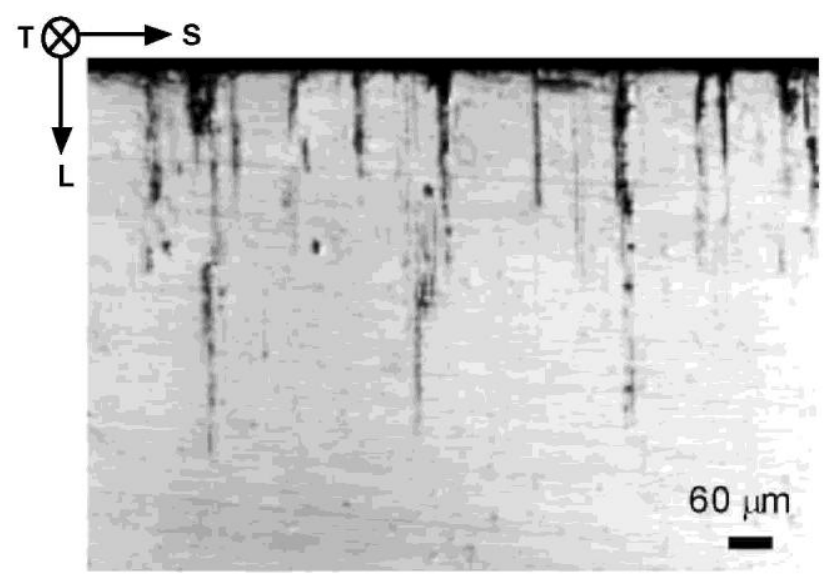

(a)

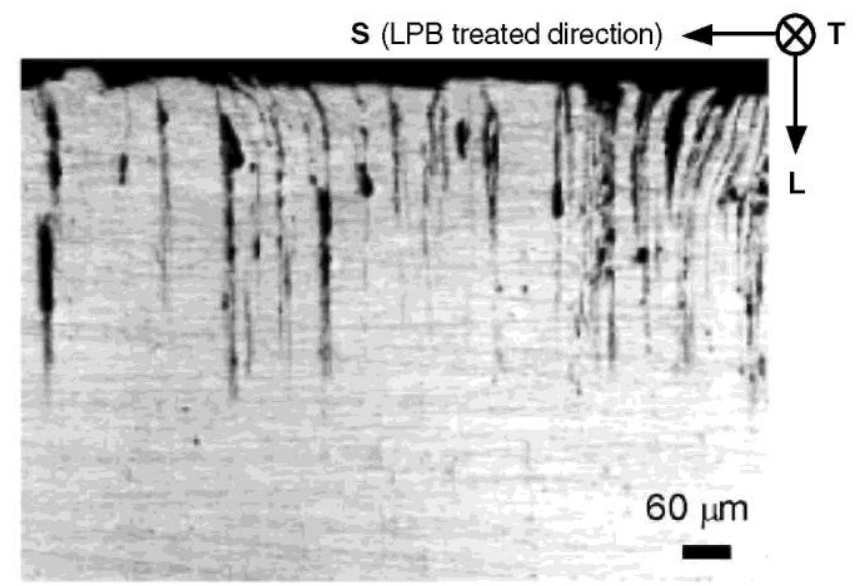

(b)

Fig. 18. Cross-sectional optical micrographs of AA2024-T3 L surfaces after potentiostatic polarization at -580 mV SCE in $1.0 \mathrm{M} \mathrm{NaCl}$ for $12 \mathrm{~h}$ : (a) no LPB treatment, (b) LPB-treated S sample.

Capillary microcell experiments facilitate electrochemical measurements on small regions. Cyclic potentiodynamic polarization was carried out at $10 \mathrm{mV} / \mathrm{s}$ in aerated $1 \mathrm{M} \mathrm{NaCl}$ using a capillary $70 \mu \mathrm{m}$ in diameter. The tested surface was the $\mathrm{L}$ cross-sectional face of a sample LPB-treated on the S surface. Note that the tested L surface was normal to the compressive stress and the primary corrosion direction was along the rolling direction of the wrought plate. As stated above, the LPB treatment produced a residual compressive stress within $800 \mu \mathrm{m}$ of the treated surface, though the sectioning probably affected the stress distribution at the sectioned surface. Measurements were made within $150 \mu \mathrm{m}$ of the LPB treated the surface and at the interior region (4000 lm away from the surface), Fig. 20. The open circuit potentials were similar in the two regions but the compressed zone near the surface exhibited higher breakdown and repassivation potentials and lower passive current density than in the interior region. These observations suggest beneficial effects of the compressive stress generated by the LPB treatment. 


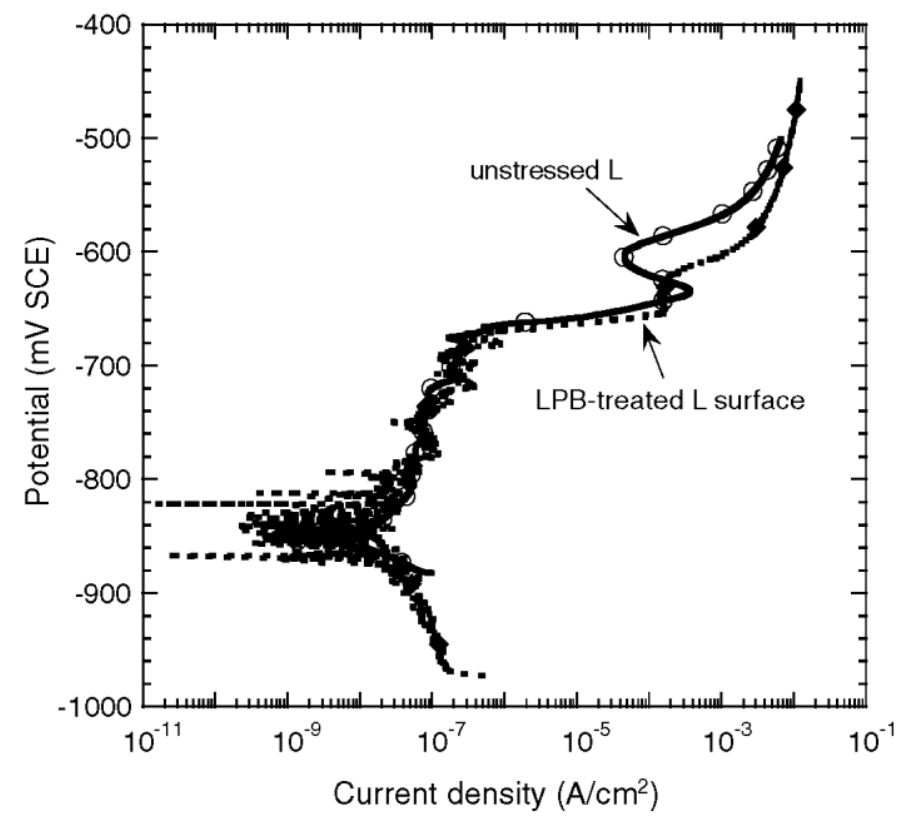

Fig. 19. Anodic polarization curves of AA2024-T3 L surfaces with and without LPB treatment in deaerated $1.0 \mathrm{M} \mathrm{NaCl}$ at $0.1 \mathrm{mV} / \mathrm{s}$.

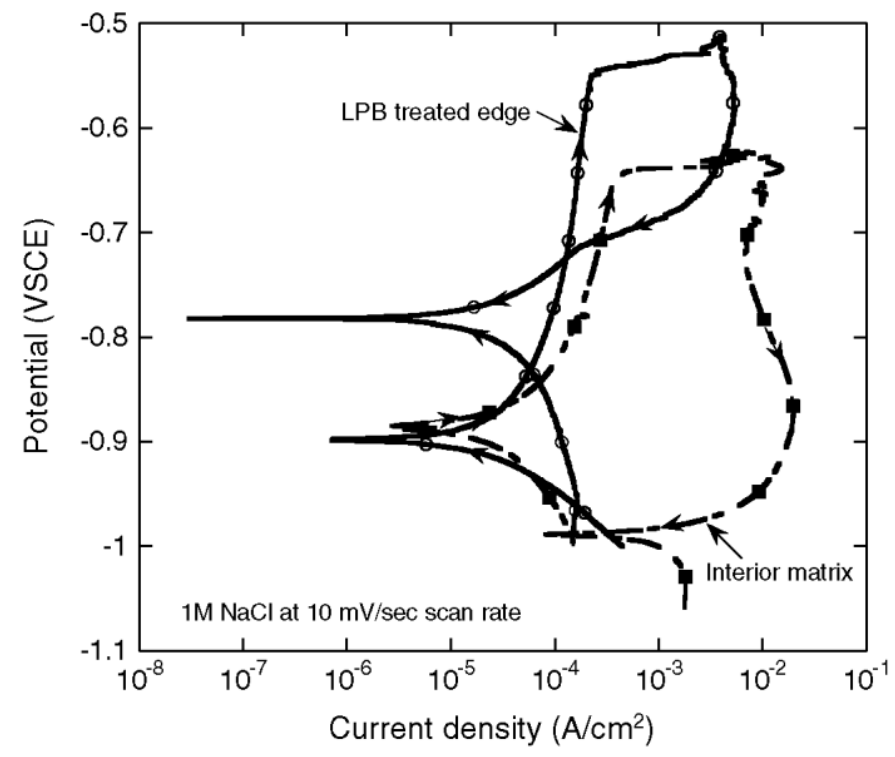

Fig. 20. Micro-capillary cell measured anodic polarization curves of AA2024-T3 L surfaces with and without $\mathrm{LPB}$ treatment in deaerated $1.0 \mathrm{M} \mathrm{NaCl}$ at $10 \mathrm{mV} / \mathrm{s}$. 


\section{Discussion}

In this study, the effects of compressive stress on intergranular corrosion have been investigated using a specially-designed compression setup. The corrosion behavior depended on the orientation and applied stress direction. For a sample compressed in the $\mathrm{S}$ or through thickness direction, which is perpendicular to the principal plane of IGC attack, the L-T plane, the rate of IGC was significantly decreased. This is expected as the stress should act to close up the IGC sites. Interestingly, the application of compressive stress half the magnitude of the yield stress did not completely eliminate IGC, which was able to continue under compressive stress at a reduced rate.

For compressed $\mathrm{L}$ and $\mathrm{T}$ samples, the stress direction was parallel rather than perpendicular to the primary grain boundary orientation along the elongated grains on the $\mathrm{T}-\mathrm{L}$ plane. Therefore, the stress did not act to close down the IGC sites. In fact, the Poisson effect should create a tensile strain in the perpendicular $\mathrm{S}$ direction. The application of very small tensile stresses in the $\mathrm{S}$ direction has been shown to greatly enhance the rate of IGC growth in the L direction [24]. So it is perhaps not surprising that the effect of compressive stress was smaller for the T sample compared to the S sample. However, IGC growth in the T direction was significantly reduced by the application of compression in the $\mathrm{L}$ direction. The difference in behavior of these two cases is not understood, but might be related to the grain dimensions in the different directions; it has previously been reported that the average grain size in this plate is 50 , 300 and $2000 \mu \mathrm{m}$ in the S, T, and L directions, respectively [28].

The effects of compressive stress on intergranular corrosion in AA 2024-T3 are associated with the effect of compression on intergranular SCC. The initiation and propagation of IGC in Al alloys have been attributed to film rupture and anodic dissolution, or hydrogen embrittlement [29-31]. In the current study, the application of compressive stress normal to the IGC significantly reduced the number of active sites and retarded the growth rate. Relative to applied tensile stress, compression makes film rupture more difficult. Moreover, compression applied in vicinity of the crack tip might delay local hydrogen entry and mitigate the possible hydrogen embrittlement [32-35]. However, the compressive stress did not eliminate IGC. The magnitude of compression studied was insufficient to fully close the intergranular sites. Dissolution could proceed under the influence of the local electrochemical conditions (grain boundary composition, potential, and electrolyte composition). The same was found with residual compressive stress. Others have shown that SCC can still occur in mild steel and stainless steel under compressive stress [36,37]. It was suggested that microscopic tensile stress exists in front of the crack tip due to the inhomogeneity of the material. The AA2024-T3 studied in the present investigation is very susceptible to IGC under the test conditions. It is possible that corrosion products cause wedge-opening effects, which are reduced, but not eliminated, by the application of a compressive stress.

\section{Conclusions}

1. The application of compressive stress at a level halfway to yield significantly reduced the growth kinetics of IGC in the perpendicular direction, but did not eliminate it totally.

2. The extent of the effect of applied compressive stress depended on the relationship between the direction of the applied stress and microstructure orientation. 
3. The effective radius change calculated from the variation of strain was a practical measure for assessing IGC growth under an applied compressive load.

4. Residual compressive stress imparted by the low plastic burnishing (LPB) technique improved the IGC resistance for certain conditions.

5. Electrochemical measurements supported the findings of the beneficial effects of compression on localized corrosion. The breakdown and repassivation potentials increased, and passive current density decreased for samples under compression or with compres-sive residual stress.

\section{Acknowledgements}

This work was supported by the United States Air Force Office of Scientific Research through Grant No. F49620-02-1-0148. The contract monitor has been Lt. Col. Paul Trulove and is now Major Jennifer Gresham. The authors greatly appreciate help from the group of Michael J. Mills in setting up the compression frame and are indebted to Paul Prevey at Lambda Research Inc. for performing the low plasticity burnishing treatment.

\section{References}

[1] M.O. Speidel, Metallurgical and Materials Transactions A 6A (1975) 631-651.

[2] R.H. Jones, Stress corrosion cracking of aluminum alloys, in: R.H. Jones (Ed.), Stress-Corrosion Cracking Materials Performance and Evaluation, ASM International, 1992, pp. 233-249.

[3] W.-Y. Chu, C.-M. Hsiao, J.-W. Wang, Metallurgical Transactions A 16A (1985) 1663-1670.

[4] J. Hahm, S.J. Sibener, Applied Surface Science 161 (2000) 375-384.

[5] M.O. Speidel, In: Proceedings of the First International Conference on Shot Peening (ICSP1), Paris, September 1981, pp. 625-635.

[6] R.D. Los, R. Eduardo, In: Proceedings of Eighth the International Conference on Shot Peening, GarmischPartenkirchen, Germany, September 2002, pp. 16-20.

[7] G.A. Hawkes, British Corrosion Journal 3 (1968) 258-261.

[8] T. Ford, Aircraft Engineering and Aerospace Technology 71 (1999) 249-254.

[9] W.-T. Tsai, C.-S. Chang, J.-T. Lee, Corrosion 50 (1994) 98-105.

[10] C.P. Chan, T.M. Yue, H.C. Man, Journal of Materials Science 38 (2003) 2689-2702.

[11] P.S. Prevey, J. Cammett, Journal of Materials Engineering and Performance 10 (2001) 548-555.

[12] P.S. Prevey, J.T. Cammett, International Journal of Fatigue 26 (2004) 975-982.

[13] V.S. Sinyavskii, A.M. Semenov, Protection of Metals 38 (2002) 132-140.

[14] Xiaodong Liu, G.S. Frankel, B. Zoofan, S.I. Rokhlin, Corrosion Science 46 (2004) 405-425.

[15] M.F. Savage, J. Tatalovich, M.J. Mills, Philosophical Magazine 84 (2004) 1127-1154.

[16] P.S. Prevey, Lambda Technologies, personal communication.

[17] T. Suter, H. Bohni, Electrochimica Acta 43 (1998) 2843-2849.

[18] T. Suter, H. Bohni, Electrochimica Acta 47 (2001) 191-199.

[19] W. Zhang, G.S. Frankel, Journal of the Electrochemical Society 149 (2002) B510.

[20] W. Zhang, G.S. Frankel, Electrochemical and Solid-State Letters 6 (3) (2000) 268-270.

[21] F. Hunkeler, H. Bohni, Corrosion 37 (1981) 645-650.

[22] F. Hunkeler, H. Bohni, Corrosion 40 (1984) 534-540.

[23] W. Zhang, G.S. Frankel, Electrochimica Acta 48 (2003) 1193-1210.

[24] Xiaodong Liu, G.S. Frankel, B. Zoofan, S.I. Rokhlin, Corrosion 62 (2006) 217-230.

[25] Xiaodong Liu, G.S. Frankel, B. Zoofan, S.I. Rokhlin, Journal of Electrochemical Society 153 (2006) B42-B51.

[26] Xiaodong Liu, G.S. Frankel, B. Zoofan, S.I. Rokhlin, In: D. Shifler, T. Tsuru (Eds.), Corrosion in Marine and Saltwater Environments II, in: The Electrochemical Society Proceedings Series, PV 2005-14, Honolulu, HI, 2004, pp. 223-231.

[27] X. Zhao, Exfoliation Corrosion Kinetics in AA7xxx Alloys, PhD Thesis, The Ohio State University, 2006.

[28] W. Zhang, S. Ruan, D.A. Wolfe, G.S. Frankel, Corrosion Science 45 (2003) 353-370.

[29] T.D. Burleigh, Corrosion 47 (1991) 89-98.

[30] D.A. Hardwick, M. Taheri, A.W. Thompson, I.M. Bernstein, Metallurgical and Materials Transactions A 13A (1982) 235-239.

[31] F. Zeides, I. Roman, Materials Science and Engineering A125 (1990) 21-31.

[32] J. Toribio, Construction and Building Materials 12 (1998) 283-287.

[33] J. Toribio, A.M. Lancha, Construction and Building Materials 10 (1996) 501-505. 
[34] P.V. Petroyiannis, Al.Th. Kermanidis, P. Papanikos, Sp.G. Pantelakis, Theoretical and Applied Fracture Mechanics 41 (2004) 173-183.

[35] P.V. Petroyiannis, E. Kamoutsi, Al.Th. Kermanidis, S.G. Pantelakis, V. Bontozoglou, G.N. Haidemenopoulos, Fatigue Fracture Engineering Material Structure 28 (2005) 565-574.

[36] W.-Y. Chu, J. Yao, C.-M. Hsiao, Corrosion 40 (1984) 302-306.

[37] W.-Y. Chu, R.-T. Ma, C.-M. Hsiao, Corrosion 43 (1987) 251-254. 